\title{
The Nexus of Energy For Free and World Society
}

\author{
Veronika Wittmann \\ Global Studies, Dept. of Modern and \\ Contemporary History, Johannes Kepler \\ University, Linz, Austria
}

\author{
Dieter Meissner \\ Dept. of Materials and Environmental \\ Technology, Tallinn University of \\ Technology, Tallinn, Estonia
}

\begin{abstract}
Recent price cuts have made photovoltaic solar energy conversion the cheapest energy source for electricity production not only in sun-rich African countries. This price fall has been achieved via traditional photovoltaic modules based on crystalline silicon wafers; and significant potential for price reduction still exists for this technology. In addition, a large number of alternative PV technologies in various stages of development promising an even higher potential for price reduction. There with the price of electricity may drop to values even lower than at times in the past when for calculating production costs the energy price had already often been basically neglected. Continuous growth by more than $20 \%$ per year could lead to another tenfold decrease in PV electricity prices until PV provides most of the electric energy worldwide. This leads to the question of the impact of basically costfree electricity.

The technological development is clear; the social and political implications are yet to even be discussed. Here, conceptualizations of World Society are used to highlight possible future scenarios. This paper should provide a first collection of thoughts on possible threats, chances and other consequences of this development.
\end{abstract}

\section{Introduction}

Both aspects of the paper - Energy For Free as well as World Society - are often considered to be long-term visions, maybe even as currently not relevant. However, we argue that both topics are set to have a strong impact on social and political developments in the near future. Additionally, as shown below, the use of renewable energies is going to require international and even global solutions.

It is paradoxical that despite obvious figures and trends proving that Energy For Free is to become a reality within a relatively short period of time, science as well as realpolitik are not paying any attention to this trend. As much as this price reduction will continue to happen faster, the already existing gap between the rate of technical and economic changes and the speed with which education and social activities change human behavior becomes dramatically wider. Therefore the early analyses of trends and foreseeable consequences are an urgent and indispensable task of current times.

The basic assumption of the paper is as follows: we live in a World Society with energy becoming basically free; both developments being Janus-faced. This Janus-face needs to be taken into account when discussing approaches of World Society as well as effects of Energy For Free. The following fundamental considerations are explanations of this basic asssumption: The scientific discourse on World Society is interdisciplinary by design. In conceptualizations of World Society, the role of Energy For Free has not even been formulated so far.

The common point of Energy For Free (based on solar energy and thereby including wind energy) and the normative idea of World Society is that both are detached from nation-state concepts. They exceed national container thinking. As such both can be labeled as visionary in current times.

This paper discusses the technical developments leading to Energy For Free as well as the political and social dimensions of it, summarizes the different schools of thought about World Society and discusses important questions concerning the nexus of the two.

The overarching goal of the paper is to understand World Society and its nexus to Energy For Free as a context, as an object and also as a challenge to social and natural sciences. The discussion given here can only be a first attempt with preliminary conclusions to initiate further investigations and research. As such no final results can be presented here, rather more questions are raised on the topic than concrete answers given.

\section{Primary Energy Supply Development}

Climate change caused by burning fossil fuels can only be limited by a quick conversion of our energy system to a solar energy-based system utilizing photovoltaic, solar thermal, and wind energy devices and/or saving energy. The conversion towards wind and solar is already happening on a worldwide scale and should continue as fast as possible to slow down climate change, as known since at least 30 years [1] but as yet has not led to major political consequences. 


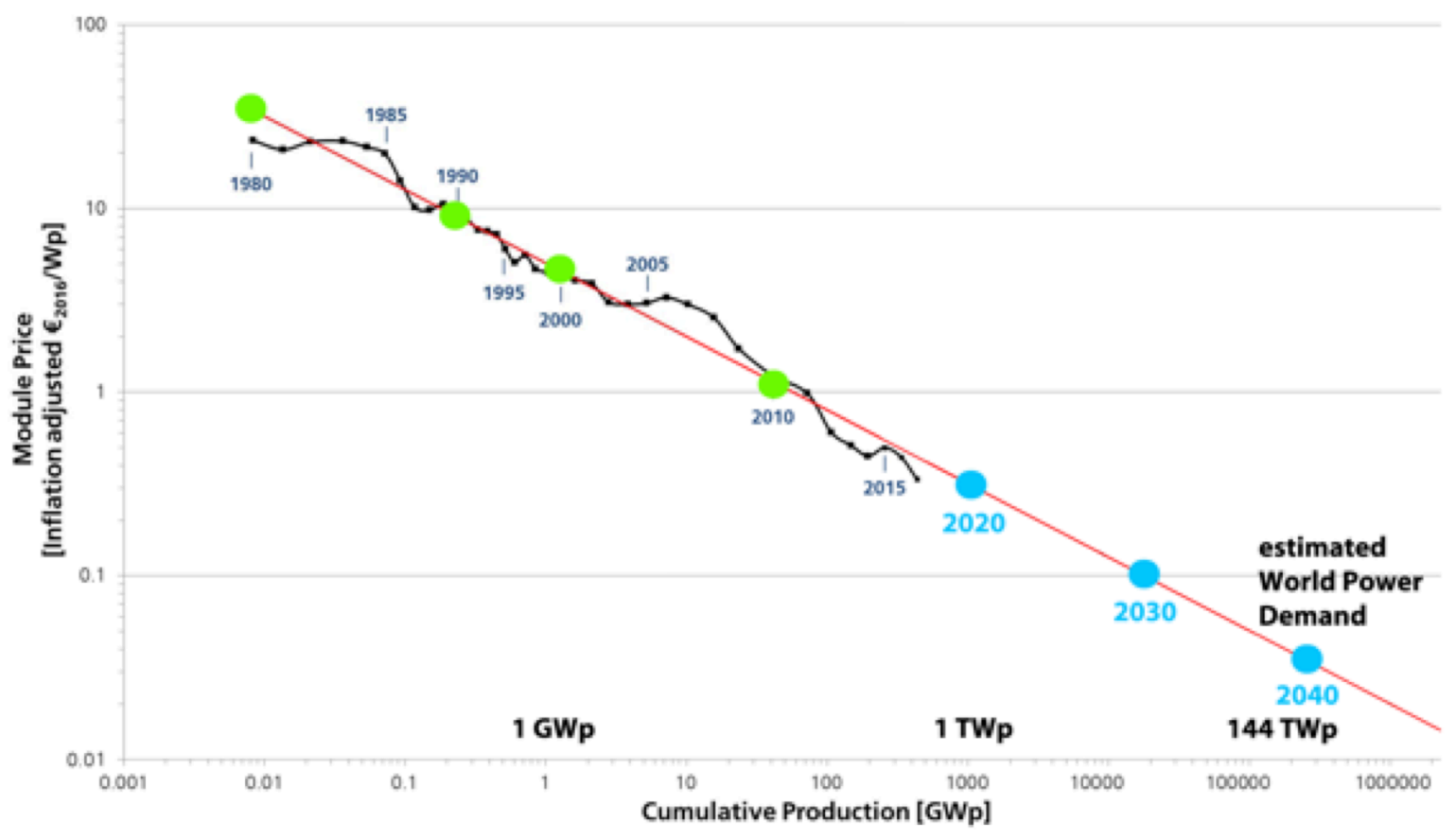

Fig. 1: Photovoltaic Module Price development in the last 35 years (Experience Curve) - extrapolated for a further 35 years

So, energy saving and rational mitigation measures - although the cheapest means of reducing $\mathrm{CO}_{2}$ emissions - have not been implemented, thereby dramatically increasing the pressure to reduce $\mathrm{CO}_{2}$ emissions worldwide.

On the other hand, solar and wind installations have grown exponentially during the last 30 years; fortunately the price of renewable electricity has decreased considerably and solar energy even today is ready to replace fossil fuels. Solar-based electricity has started to compete with conventional forms of electricity and has already become cheaper than nuclear and coal-based electricity - not only in sunrich countries like Dubai. Here in May 2016 the lowest unsubsidized bid for an $800 \mathrm{MW}$ power plant was $3 \mathrm{U}$. S. cent $/ \mathrm{kWh}$, directly comparable with a 4.5 cent $/ \mathrm{kWh}$ for a coal-fired power plant in Dubai tendered in October 2015. Even in Germany the lowest costs of PV-based electricity (the electricity generation costs) are below those of all fossil- and nuclear-based costs in 2018. [2]

Fig. 1 shows the development of photovoltaic module prices over the last 30 years in a so-called "Experience Curve" (in photovoltaics often called "Price Learning Curve") as produced by Germany's leading solar energy research institute, the Fraunhofer ISE. [3] The prices of photovoltaic modules are given as costs of a module, which under standard test conditions would produce an electric power of $1 \mathrm{~kW}$. So for high-efficient (monocrystalline silicon) modules it means a relatively small module area (e.g. $4,4 \mathrm{~m}^{2}$ ), for low- efficient (amorphous silicon) modules it means a relatively large area (e.g. $16 \mathrm{~m}^{2}$ ).

It shows a price decrease by about a factor of 50 in the last 35 years (from about $20 € / \mathrm{kWp}$ in 1980 to less than $0.3 € / \mathrm{kWp}$ in 2017 , a learning rate of $24 \%$ over 37 years). Assuming a constant growth rate, we extrapolated the curve until 2040, when the prices are expected to fall below 3 Euro-cent per Wattpeak, which would mean roughly another factor of 10. Around this time enough PV modules (about 144 $\mathrm{TWp}$ ) would be produced to cover world energy demand. With this growth rate, a world energy demand of about 30 TW could already be covered by photovoltaic electricity before 2040. In order for a continuous energy production of $30 \mathrm{TW}$, an installed module production capacity of $144 \mathrm{TWp} / \mathrm{a}$ would be needed, assuming no additional losses due to energy storage and an average capacity factor of 0.21 .

Of course this is a very bold extrapolation without a solid database, justified only by the linear decrease in the past. Also, there is no direct relationship between PV module costs as discussed and the electricity production costs using these modules. Additional costs such as those for installation, the electricity grid, the ground area needed for installation and the costs of capital need to be taken into account. However, the calculation of precise values such as the leveled cost of electricity (LCOE) is beyond the scope of this paper and estimates can be found elsewhere. [4] Nevertheless, these studies are all in general intentionally "conservative", which very often means the effects are underestimated considerably. Also, since the solar power available in 
different regions depends on local weather conditions, detailed geospatial investigations of local conditions would be needed based on local performance studies.

A key new issue of importance will be the storage of energy. As long as the prices of battery systems are as high as today, this will limit the price dumping of electricity during certain hours of the day. However, during sun-hours in Europe today the electricity prices have already dropped below zero, customers are being paid to take electricity from the grid. On the other hand, we foresee a similar price drop for batteries as has happened for photovoltaics, especially when the economy of scale becomes important.

All these developments also need to be closely observed and analyzed within a time horizon of more than 10 to 20 years. An example of a too-short analysis time is the in part even visionary book "Low-cost Solar Electric Power" by L. M. Fraas, who does not even discuss the consequences of the dramatic cost reductions of solar electricity. [5]

Since we also expect storage costs to drop considerably in the future, and in addition that the decentralized use of renewables will make expensive electricity grid costs superfluous, we understand the term Energy For Free to be shorthand not only for free primary energy or free energy supply, but also for very low end-user costs.

As yet only China is already actively working on a free environmentally friendly energy network called the Energy Internet where information and energy are integrated in depth called We-Energy with the clear aim of ,zero marginal cost”. [6]

Figure 2 illustrates the property rights discussion needed for the renewable energy sources sun, wind and running water, as they enter the air space above a certain ground area, as in many countries the underground energy sources based on fossil fuels are already covered by national laws. One of the many open points in new legal questions is access to renewable resources. National regulations as yet deal with the volume of earth beneath a certain land area (compare Fig. 2), i. e. the property rights of underground, mainly material resources, e.g. fossil fuels. Very little is as yet defined as to the volume of atmosphere above the ground [9]. National laws dealing with access to water are very often a field of conflict or even war between states. However, access to solar radiation is regulated in completely opposite ways: in California the owner of PV installations may even demand the removal of buildings or trees shadowing these installations, whereas in Germany even the construction of new buildings shadowing such installations is not limited.

Especially if plans to install very large solar satellites become reality, casting large shadows onto earth, but already for large kites to use wind energy,

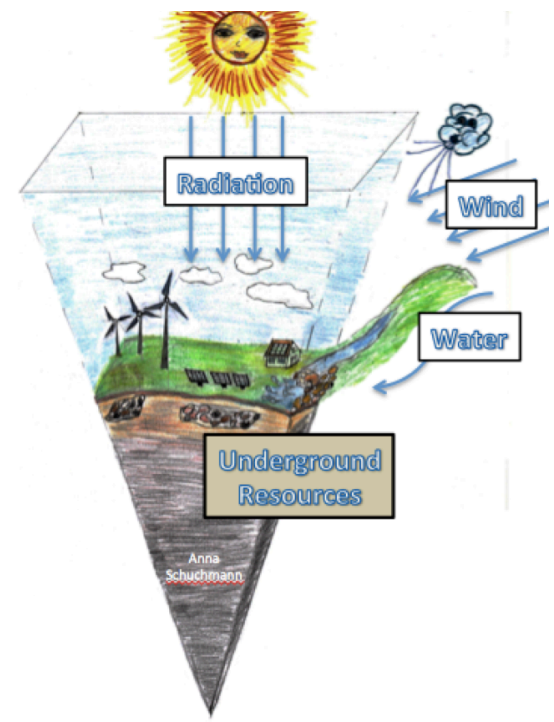

Fig. 2: Land ownership and access to Renewables (drawing by A. Schuchmann)

the question of access to primary energy resources requires international collaboration and international legislation. Discussing these issues is one of the many questions that should be dealt with not only on a national level.

However, problematic or even negative aspects of Energy For Free also need to be addressed such as the loss of incentives for rational and efficient use of energy, energy saving, energy (light- and heat-) pollution and local and micro-climate change, increase of transportation and traffic, environmental destruction by extensive mining due to the low cost of the energy required, low-cost plastic pollution, etc.

Energy costs currently still prevents many energyintensive activities, which in the future will have to be restricted by regulations and laws. Otherwise Energy For Free would allow everybody to destroy ecology for profit by filtering Gold from seawater, inert gases from air etc.

Currently fossil fuels (coal, oil, natural gas) and biomass are owned by the landowner and are thereby national assets. For todays renewables this is still the case in principle since the price of the traded form of energy - the electricity - is determined by the cost of the primary ground-based conversion system, which is in general owned by the landowner or the country, respectively.

This will change in the Energy For Free system of tomorrow when the prices of these systems (PV systems, wind generators etc.) become basically negligible. It will probably lead to an abundance of conversion systems. Here on the one hand access to the primary source - i.e. solar radiation, wind or water - becomes critical (e.g. satellites or kites compete with ground-based systems). On the other hand access to electricity grids may still be 
controlled by monopolies or states. The height of PV and wind generators may need international agreements but still be a matter of dispute as can be seen for the flyover rights in air traffic. Finally even the national approaches of today may have to be replaced by transnational planning and legislation. A world-wide electricity grid - possible, should superconducting cables become available to eliminate the need for electricity storage - would best be controlled if national governments were replaced by a transnational government that has World Society as its focus.

\section{The Political and Social Dimensions of Energy For Free for All}

The use of solar energy does not require extremely complicated technology. Even economically weak states can afford it. Solar energy tools can be set up anywhere. More than $80 \%$ of photovoltaics are produced in China at present. However, instead of the dissemination of this technology there is monopolization, as nearly all installations are built in China.

Regarding the political dimension one negative consequence of Energy For Free for all might be the destabilization of the current system. Autocratic political systems may collapse. This may lead to an empowering of currently poor and dependent developing countries. Energy-autarkic states may become possible nearly everywhere; the potential negative aspect of this trend is that internationally stabilizing dependencies and trade ways and the collaboration of countries may disappear. Thereby energy would lose its role as a "lubricant" of world economy and politics. If Energy For Free becomes reality, independence may be interpreted as a destabilizing factor that might lead to destabilization.

With reference to the social dimension, poor people will get access to energy. At the same time land ownership will gain importance due to the fact that land is needed to build solar panels and wind

\begin{tabular}{|c|c|}
\hline $\begin{array}{l}\text { - Decentralization } \\
\text { - Oil-based Autocratic systems } \\
\text { collapse } \\
\text { - Empowerment of developing } \\
\text { countries } \\
\text { - Energy autarky becomes } \\
\text { available } \\
\text { - Energy-poverty ends } \\
\text { - Access to energy for all } \\
\text { - Current legal frameworks } \\
\text { become obsolete }\end{array}$ & $\begin{array}{l}\text { - Monopolization } \\
\text { - New Superpowers form } \\
\text { - New dependences appear } \\
\text { - Less transnational trade and } \\
\text { cooperation } \\
\text { - Misuse of Energy-surplus } \\
\text { - Land-ownership prevents use } \\
\text { for the poor } \\
\text { - New legislation can restrict } \\
\text { access }\end{array}$ \\
\hline
\end{tabular}

Fig. 3: The actors needed for a global energy agenda generators.

Once energy does not cost anything anymore, there will still remain the question of the power of disposition of means of production, storage and transport of energy (e.g. electricity). This is currently mainly a question of distributive justice of land ownership and the power of disposition. A conflict scenario may arise regarding the question: who has access to land and who does not. The clash of power is therefore about communal land and private ownership. In this respect, new conflict scenarios will arise due the change in technology.

\section{The Term World Society}

The history of the term World Society is still a largely unwritten one. There is as of today no comprehensive historical analysis of the history of the concept in existence. To this end, the term World Society is one that has so far left no appreciable conceptual historical trace. Theresa Wobbe [11] refers to the sociological reception of the term and the concept of World Society as still very diffuse. In her view, both its conceptual foundations as well as the theoretical assignments are not clear. Thus we find World Society to be equated with the unit phantasm of systems theory, or there are considerations associated with World Society that give little attention to the sociological concept of context, as Theresa Wobbe notes on the work of Ulrich Beck.

Semantic-related investigations deal with concepts; that is, of terms such as globalization or World Society, in which this inevitably means that it is not the subject of globalization or World Society that is the subject of interest, but rather the terms and concepts by which they are described and claimed. Terms help to describe statements as well as to classify. But concepts themselves are by no means already the same as statements [13].

Given the different conceptualizations of World Society and the varied use of the term, the approaches are first juxtaposed and placed in an interpretative context. Analogous to the various conceptualizations, the respective uses can be categorised into subgroups. A large area includes those scientific approaches in which World Society is seen as an additional layer to 'national societies'. In the discussions on global governance, one often finds such uses of the term in connection with the nation state. Dirk Messner [14] refers both to World Society as well as to global economy as institutionally underdeveloped, and he starts from the assumption that the future world society will not be a 'globally extended nation-state', the world economy no international expanded economy, and the developing project of the global governance system not a 
magnified image of democratic constitutional states. Here World Society is projected into the future described as not a globally extended nation-state. Contrary to this is the use of a term, which was developed based on Niklas Luhmann's intellectual tradition of systems theory. Here world society is described as an $18^{\text {th }}$ century European idea. As a conceptual innovation, it reflects on the development of a European system of states in the early modern period. Perception takes the place of the universal entitlement of an individual state, thus does not arise in the sum of all interactions between any two states [15].

The concept of World Society may be described as a term that is relatively independent from the state sphere in which multicultural society reaches its highest degree of heterogeneity. World Society is still no world state, the formation of which is hindered or blocked by the continued existence of any state which defends its sovereignty and autonomy (possibly even in a military way). World Society at the same time includes all existing different cultures. In it, multicultural society reaches the highest degree of heterogeneity.

If the concept of World Society is understood to be the comprehensive system of human society [17], then society can only be formed uniformly across the globe. The implications of this situation for the concept of society itself (e.g. a setting aside of the characteristics of political constitution and social cohesion) are controversial and are discussed fiercely in scientific debate. The concept of World Society is not without controversy, and one cannot omit the reservations which the society component of the term already encountered.

The following description of the concept of World Society pertains particularly to the theoretical basic understanding of the different schools of thought about the term. [18]

The concept of World Society may be described as a term relatively independent from the state sphere in which the multicultural society reaches its highest degree of heterogeneity. Karl-Heinz Hillmann [19] argues e.g. that World Society is still not the same as a world state, the formation of which is hindered or blocked by the continued existence of any sovereign state, which defends largely its sovereignty and autonomy (possibly even in a military way). At the same time, World Society encompasses all existing different cultures.

The concept World Society can be represented with respect to its use in socio-scientific disciplines: The term refers to a teaching and research area in sociology that interacts closely with neighboring disciplines such as political science (international relations) and philosophy (social philosophy, political philosophy). [20]
World Society is a concept that allows a wide range of social-theoretical assumptions and therefore eludes a simple definition. In socio-scientific discourse which deal analytically or normatively with World Society, the term is controversially discussed.

The discourse on World Society has differentiated increasingly since its beginning. However, two basic perceptions have remained significantly with the different approaches: on the one hand the core thesis of system theory of the singularity of World Society, and on the other hand the variety of conceptualizations emanating from the emergent World Society; alongside with this the nation-state or regional societies also continue to have validity.

With respect to theoretical understanding, the differences can be classified in the following approaches (Fig. 4):

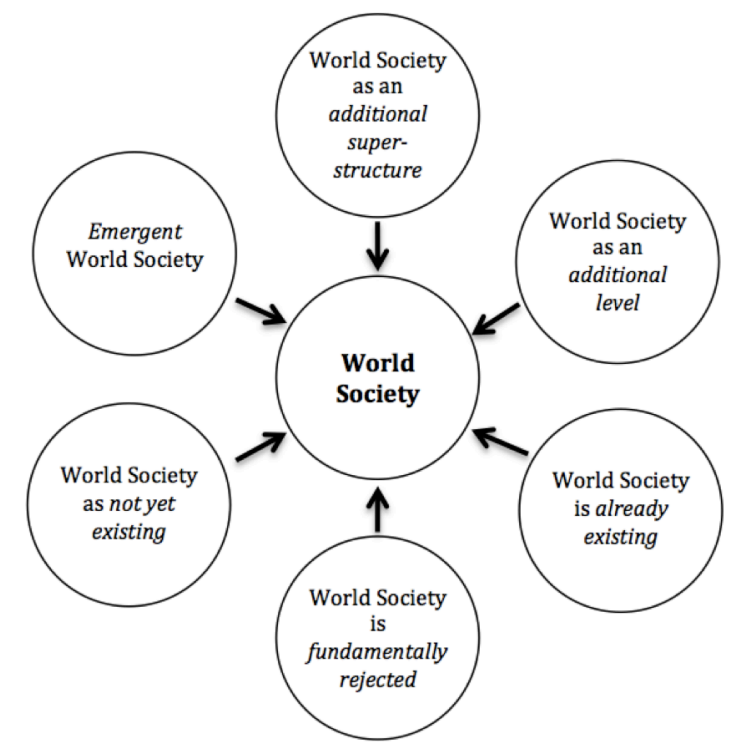

Fig. 4: The six different views on World Society

First view: The majority of scientists see no more than merely approaches to a formative, emergent World Society in the empirically verifiable compression of transnational interactions in a "postnational constellation". [22] The basic idea in their analyses is that, despite the globalization of the social-with-concomitant homogenization, the basic prerequisite for a social formation (which would deserve the name World Society) is social integration and cohesion. World Society therefore does not yet exist. Societies exist only in the plural form. Here the concept of World Society is used as an emergent World Society. Energy For Free would at this point be perceived as a concept that may lead to the end of energy poverty and that can enable social integration and cohesion.

Second view: Some scientists have as a reference point for their analyses the notion of world ethics based on the idea of the universality of human rights. 
The latter has its basis in the perception of Immanuel Kant and his notion of a "world citizenship". The sociologist Ulrich Beck designed the concept of a "World Risk Society" whose risk diversification no society is able to escape anymore. [23] In this respect - as an additional superstructure - the concept of World Society is used. In world risk society, energy can be interpreted as a tool for political protest as well as a sign of risk. Here, if people continue to use fossil fuels, the whole world - under the conditions of climate change - is at risk of collapse. Civil society organizations would lobby for renewable energy sources and Energy For Free would reduce the global risk of facing ecological collapse.

Third view: A singular existence of World Society is contested by two other approaches, whose basic idea is the worldwide diffusion of institutional patterns on the one hand and the dominant position of global structures on the other. The latter view is found in approaches of world system theory, based on the primacy of the capitalist world economy. [24] The global diffusion of an institutional pattern is a supporting element in neo-institutionalist approaches. [25] In both views, the concept of World Society is used as an additional level. In the perception of the world system analysis Energy For Free would finally lead - due to the capitalist economy - to the monopolization of renewable energy infrastructures. Economically rich countries would dominate this type of energy, whereas countries on the periphery would not be able to participate and profit from this technology. In the approach of the world polity, alternative forms of energy would be set up as an institutional model that would finally reach worldwide recognition by diffusion. Questions about the costs of energy forms would not be raised here; only the formal structure and the institutionalization of Energy For Free as a global model are important.

Fourth view: Political scientists in the field of international relations deal with the growing interdependence of nation-state-organized societies and reflect on the emergence of a trans-national networked civil society. Based on their empirical results, however, they assume at most the emergence of a World Society. Thus, the conclusion was drawn from the transformation of world politics after the end of the bipolar world order that a new triad of "A World of States, an Economic World and a Societal World" was emerging resulting, but no World Society. [26] Here the concept of World Society is used as a not-yet-existing World Society. The greater importance of renewable energy would here be the result of a well-functioning network between responsible governments and economies as well as an active civil society. Energy For Free would here be a desirable form of energy supply.
Fifth view: The idea of an existing World Society is also rejected by representatives of the "realistic school" of international relations, just as the concept of global governance or the vision of a world state was rejected in which the discourse of World Society, especially among political philosophers, frequently results. [27] Here the term of World Society is fundamentally rejected and classified as visionary. Representatives of the "realistic school" would reject any idea of Energy For Free as illusory. The vision of a fair distribution of renewable energy among all citizens of the world would be labeled as a phantasm.

Sixth view: System theory, which is based on the analyses of Niklas Luhmann, takes a radical break from all these social-theoretical approaches, basically emanating only from a single society in the world: World Society. This is designed to be the most comprehensive context of human coexistence, accommodating all social processes and figurations within it. System theorists assume in the wake of Niklas Luhmann that World Society already exists, and indeed in the singular and not the plural of partial worlds. [28] This core thesis of the singularity of World Society means turning away radically from the plural concept of society. Here the concept of World Society is used for an existent World Society and is stringently expressed only as a singular form of society. In the system-theoretical approach, energy would be considered as a functional system. The code would be the same as it is in the functional system of economy - being to have/to have not. The program would be scarcity versus abundance. The medium of this functional system would be the fight for political power. And finally, the function of energy for the whole system of World Society would be as a medium for development.

Despite this diversity of theoretical assumptions and empirical findings, however, all world social theories agree in principle that a thorough analysis of the processes of societal change requires the recourse to a global context. This means not least overcoming methodological nationalism.

For social science theory and empiricism in general, as well as natural science, the handling of global structures, processes, fields and areas of action are considered to be one of the most complex scientific challenges of our time.

\section{Discussion:}

A progressive decrease in the cost of photovoltaic (and at least to a certain extend wind) energy systems will lead to cheaper and cheaper electricity costs and basically Energy For Free. Already today photovoltaic electricity costs are lower than those of all other energy resources. This technological development will require worldwide political, socioeconomic and legal agreements. We consider the 
social framework of this technological trend to be World Society. Fair and equal solutions can only be found on an international and worldwide scale.

It needs a variety of actors to reach a sustainable design for a renewable energy world. Besides states and the private sector, civil society organizations will be of increasing importance. Their role will be decisive in future decisions. Here we are referring to discussions on global governance, which assume a fundamentally changing role of states and which also include transnational cooperation. Concerning the private sector, responsible enterprises have to respect social and ecological standards.

Regarding the question of distributive justice, the core topic will be: Who will profit, who will lose. A more detailed investigation of the possible winners and losers of a change to Energy For Free will be needed. The question of who will win and who will lose will be determined by the legal framework, the economic conditions as well as the realpolitik. An international and global solution should be preferable in order to ensure that everybody profits.

A rational use of energy will in any case become rather more difficult to realize with falling energy prices, threatening the transition to sustainable development. As much as Energy For Free for all might seem at a first glance to be a positive trend towards a more equal world, there are also negative strings attached. The risk is that if something does not cost anything anymore it may lead to a situation in which short-term profit wins over sustainable future designs. Energy for Free will take place whatever the circumstances are. But the negative consequences of this development need to be mitigated.

A global energy agenda would need a strong and functioning institutional and legal framework. The one and only international organization that could deal with such an endeavor is currently the United Nations Organization. Their "Sustainable Development Goals" (SDGs) actually refer to the topic of energy quite prominently in Goal 7 . Interestingly enough, this goal only refers to energy as it relates in nexus to renewable energy as a criterion for sustainability. Goal 7 does not refer at all to the reduction of fossil fuels and the cost reduction connected with increasing amounts of solar energy in the global energy mix is also not reflected. Energy for Free is not being mentioned at all in that SDG. Even solar energy, which is already the cheapest of form primary energy carriers, is not addressed in this discussion. Furthermore, there is no clear connection in the SDGs between use of fossil fuels and climate change [30]. These topics will be discussed in a later paper.

As yet there is a lack of consciousness concerning the current development of the energy sector towards Energy For Free the topic is not listed in the SDGs.
Furthermore, the one and only global organization in the world that could provide an institutional framework to deal with these developments - the United Nations - have not paid any attention to the theme.

The SDGs can be seen as a strong rhetorical agenda of the international community, where energy is a goal of its own. The difficulty is the implementation of the goals. And in the end this is a question of political will. States are the main political players in the process of implementation, but only on the surface. Besides states, the private sector - i.e. enterprises as companies or multinational groups, as well as civil society are actors. As a civil society we define all non-governmental organisations acting on a local, national, regional or global level. Here the private sector is by far the most dominant player, since this sector is global capitalism; private companies aim at profit maximization. The state strives for particular interests and wants to stabilise its power. Different states have different political systems: they include dictatorial regimes, authoritarian regimes, democracies etc. The interesting question will then be who may act as the main force for creating a global energy and final sustainability agenda. Here we foresee only civil society as a driver for change (compare Fig. 5).

With respect to SDG 7, "universal access to affordable, reliable, sustainable and modern energy", the change towards renewable resources will happen because of its low cost. Civil society in the context of sustainable development needs to direct falling energy prices towards the benefit of all humanity. Civil society here stands for non-governmental organizations; community based organizations as well as grassroots movements. Although we think that the probability of sustainable energy use will be higher if it is controlled by civil society, this is far from self-evident.

None of the players listed above - states, private sector and civil society - will be successful in implementing a global energy agenda, if they only focus on a nation-state or local context. A global perspective is essential for a really sustainable development. The multi-lateral cooperation of states is thereby indispensable. A comprehensive body of legislation in order to control all players is the fundamental basis for a global energy development towards sustainability.

Another aspect besides who is profiting from Energy For Free is also the question of what the energy will be used for. The utilization of energy for purposes leading to the destruction of the environment, cultures and social structures is a misuse of energy. This misapplication of energy would in principle be far easier for everyone the moment Energy becomes For Free. One example might be the filtering of sea water to extract gold, 
thereby threatening all life in it. The disposition of energy for all makes it more difficult to prevent the misuse of energy.

\section{Conclusion:}

The world may get fairer due to the fact that energy will become free for all; many energy-based socio-economic disparities will vanish. In addition, a profound change in world politics will take place. However, enabling improvements for all also means enabling all to misuse energy, especially to destroy the environment and nature. Thus, transnational regimes are needed and require worldwide acceptance of regulations and legal systems, empowering the World Society.

International soft-law will not be sufficient. Transnational actors as well as worldwide networks already play an important role in fighting climate change and in lobbying for renewable energy. By doing so they are since a long period of time important actors in the process of constituting a World Society. The anti-nuclear movements in different countries of the world have always had a global goal in mind: to abolish the use of nuclear energy around the globe. The same would apply to environmental movements. All of these civil society organizations have been at the forefront of transnational activities and can be considered as important protagonists of World Society.

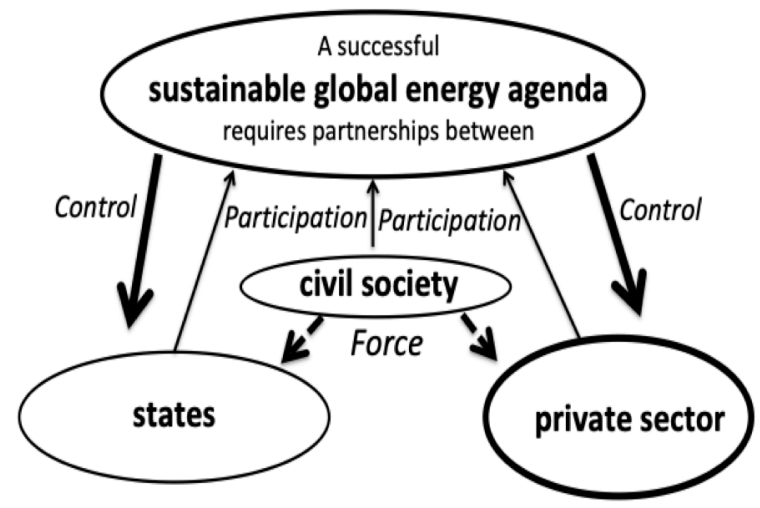

Fig. 5: The actors needed for a global energy agenda

This paper presented different views on World Society as well as on the movement towards Energy For Free. We highlighted the political and social dimensions of this technological trend. Our statements should be understood as a call for discussion on the energy future of the world, thereby we strongly advocate for transnational and international cooperation among different actors in order to achieve a fair and sustainable energy system in World Society.

\section{References}

[1] M. I. Hoffert et. al.: "Energy Implications of Future Atmospheric Stabilization of $\mathrm{CO}_{2}$ Content", Nature 395, 1998, pp. 881-884.

[2] C. Kost et al., Stromgestehungskosten Erneuerbare Energien, FhG-ISE, Freiburg, Germany, 2018.

[3] FhG ISE: Photovoltaic Report, 15.6.2018, slide 43, https://www.ise.fraunhofer.de/content/dam/ise/de/docu ments/publications/studies/Photovoltaics-Report.pdf.

[4] FHG-ISE, Current and Future Cost of Photovoltaics, 2015, and Levelized Cost of Electricity, FHG-ISE, Freiburg, Germany, 2013.

[5] L. M. Fraas, Low-Cost Solar Electric Power, Springer Int. Publ., Cham, Switzerland, 2014, p. vi.

[6] Qiuye Sun, Energy Internet and We-Energy, Springer Nature Singapore Pte Ltd., Singapore, 2019

[7] D. N. Reinhardt, "The Vertical Limit of State Sovereignty", J. Air L. \& Com. 72, 2007, pp. 65-137.

[8] T. Wobbe, Weltgesellschaft, transcript Verlag, Bielefeld, Germany, 2000, p.7.

[9] D. Messner (ed.), Die Zukunft des Staates und der Politik. Möglichkeiten und Grenzen politischer Steuerung in der Weltgesellschaft", J. H. W. Dietz Nachf., Bonn, Germany, 1998, pp. 9-10.

[10] N. Luhmann, „Gesellschaft“ in W. Fuchs-Heinritz et al. (eds.), Lexikon zur Soziologie, $3^{\text {rd }}$ ed., Westdeutscher Verlag, Opladen, Germany, 1995, p. 235.

[11] R. Stichweh: „Die Weltgesellschaft. Soziologische Analysen“, Suhrkamp Verlag, Frankfurt am Main, Germany, 2000, p. 7.

[12] K.-H. Hillmann: „Wörterbuch der Soziologie“, 5th ed., Kröner Verlag, Stuttgart, Germany, 2007, p.959.

[13] V. Wittmann: „Weltgesellschaft“ in „Kleines Lexikon der Politik“ ed. by D. Nohlen/F. Grotz (eds.), 6th ed., Verlag C.H. Beck, München, Germany, 2015, pp. 734736 and 685-687.

[14] J. Habermas, Die postnationale Konstellation, Suhrkamp Verlag, Frankfurt am Main, Germany, 1998

[15] U. Beck, Weltrisikogesellschaft, Suhrkamp Verlag, Frankfurt am Main, Germany, 2007.

[16] I. Wallerstein, The Modern World-System: Capitalist Agriculte and the Origins of the European World Economy in the Sixteenth Century, Academic Press, New York, USA, 1974

[17] J.W. Meyer in G. Krücken (ed.), Weltkultur - Wie die westlichen Prinzipien die Welt durchdringen, Suhrkamp Verlag, Frankfurt am Main, Germany, 2005.

[18] E.-O. Czempiel, Weltpolitik im Umbruch. Das internationale System nach dem Ende des Ost-WestKonflikts, C. H. Beck, Munich, Germany, 1991.

[19] M. Lutz-Bachmann, J. Bohmann (eds.): Weltstaat oder Staatenwelt? Für und Wider die Idee einer Weltrepublik, Suhrkamp Verlag, Frankfurt am Main, Germany, 2002.

[20] World Commission on Environment and Development, Our Common Future: From One Earth to One World. www.un-documents.net (14 May 2018).

\section{Acknowledgment}

We thank Anna Schuchmann for her drawing in figure 2. DM acknowledges financial support by the European Regional Development Fund, Project TK141. 